\title{
Mining Robotics
}

Joshua A. Marshall

\section{Synonyms}

Mining automation; Automated mining; Automated resource extraction

\section{Definition}

Mining robotics refers to the full automation, semi-automation, or remote control of mining equipment, including both fixed and mobile machines, towards improving the feasibility, safety, productivity, and efficiency of modern mining operations.

\section{Overview and Challenges}

Mining is the practice of extracting minerals and other valuable materials from the Earth's crust—or, in future, possibly from extraterrestrial bodies— to the benefit of humankind. Modern mining operations involve heavily mechanized processes that employ large diesel-driven, hydraulic, and/or electrically-actuated equipment. What is more, these industrial machines must operate in harsh, dynamic, and uncertain natural environments that may also pose persistent physical and health risks to humans. Thus, the use of robotics in mining is not only about the potential to improve efficiency and productivity through automation, but is also about removing humans from unpleasant and potentially dangerous working conditions. However, the challenging environments found in mining activities often preclude the use of existing techniques from other industries that employ robots (Lever, 2011, p. 806).

Joshua A. Marshal

Queen’s University, Kingston, Ontario, Canada e-mail: joshua.marshall@queensu.ca 
For a broad introduction to the fundamental stages of mining and what drives technology development—including the use of robotics—in mining, see Marshall et al (2016, Section 59.1) and references therein. Generally put, mining methods can be divided into two broad categories: surface mining and underground mining. Surface mining methods are used when the valuable material—called ore-lies near to the surface. Surface mines are usually large scale operations that have high production rates. Underground mining methods are used when the sought after ore is deep below the surface. Underground methods usually have lower production rates and are usually more technically challenging and hazardous operations. The types of equipment used and the operating environments, and thus the application of robotics to mining, differs between these two types of mining methods.

\section{Robotics in Surface Mining}

Surface mines are usually high-tonnage operations that involve the use of massive mobile equipment for excavation and haulage, in combination with fixed materials processing (e.g., crushers) and transportation (e.g., conveyors) infrastructure. In surface mining, the automation of mobile equipment typically relies on the use of high-precision GPS (possibly augmented by pseudolites in deep pits), onboard radar and/or LiDAR for situational awareness and obstacle detection, as well as the widespread availability of wireless communication systems.

Fully autonomous haul trucks, now widely available as commercial products sold by several well-known mining and construction equipment suppliers, are effectively large mobile robots that must operate in challenging and dynamic outdoor scenarios, including in the presence of dust, fog, and extreme weather. The robotic systems on these trucks solve the usual problems of sensing and perception, situational awareness, localization, and control. Although some companies demonstrated autonomous driving for mining haul trucks as early as the 1990s (Chadwick, 1996), it was not until 2008 that the first commercial deployment occurred (Marshall et al, 2016). Since then, mining giants Rio Tinto and BHP have already deployed dozens of autonomous trucks in Australia, Chile, and Canada. Some equipment suppliers have recently gone so far as to completely remove the operator's cabin from some of their automated vehicles in order to create machines designed solely for automated driving. For example, Fig. 1 shows Komatsu's "Innovative Autonomous Haulage Vehicle", a large mobile robot revealed to the public in 2016.

Large blasthole surface drills have also been the focus of automation and robotics efforts for surface mining operations. These drills are usually large tracked vehicles that include an articulated mast that houses the the drilling components (i.e., drill motor, rods, and drill bits). There are several parts of the drilling process that are amenable to automation, including not only autonomous drilling functions, but also robotic tramming functionality (i.e., autonomous driving from one hole to another) and coordination of multiple drill rigs (Mansouri et al, 2016). Several drilling equipment suppliers now offer automated surface drills. For example, Atlas Copco Rock 


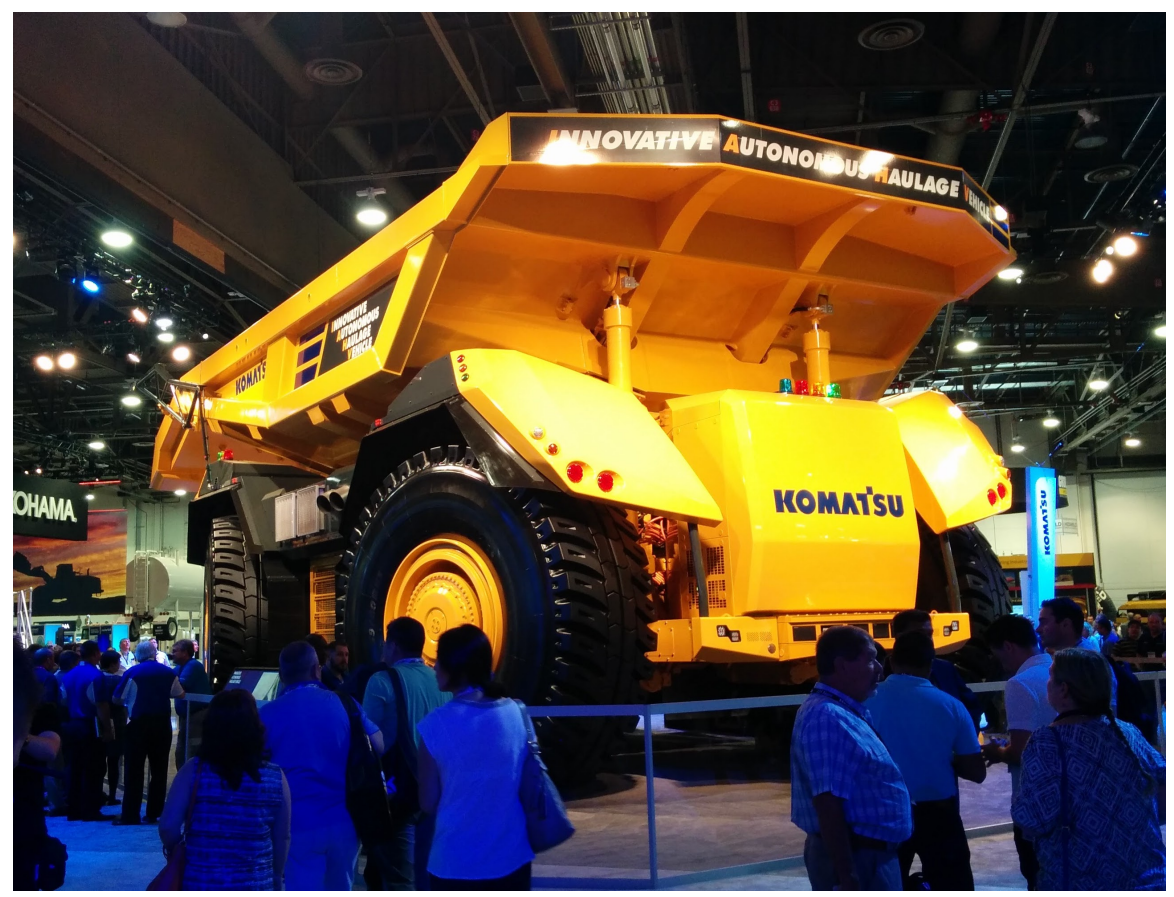

Fig. 1 Komatsu's cabless autonomous haul truck, named the "Innovative Autonomous Haulage Vehicle" and revealed at MINExpo International 2016 [courtesy of Laeeque Daneshmend, 2016].

Drills AB released not only a completely autonomous, but also cabless blasthole drill in 2016, shown in Fig. 2.

In addition to autonomous haulage and robotic blasthole drilling-which have arguably garnered the most attention technical and public attention-surface miners have also applied techniques from robotics towards the development of autonomous and remotely operated dozers, multivehicle fleet coordination systems, telerobotic rock breakers (Duff et al, 2010), as well as the automation of large dragline excavators and other large surface excavation machines (Marshall et al, 2016).

\section{Robotics in Underground Mining}

In contrast to surface mining, underground mines are characterized by vast networks of relatively narrow underground tunnels (called drifts and crosscuts) that are usually dark, wet, often hot, and deep underground (sometimes up to $3 \mathrm{~km}$ ). Such environments preclude the use of GPS or other satellite-based navigation systems as well as the use of localization systems based on line-of-sight or radio signals (e.g., due to shadowing and multipath issues) (Marshall, 2010). However, these harsh environments together with the inherent repetitive nature of the load-haul-dump cycle 


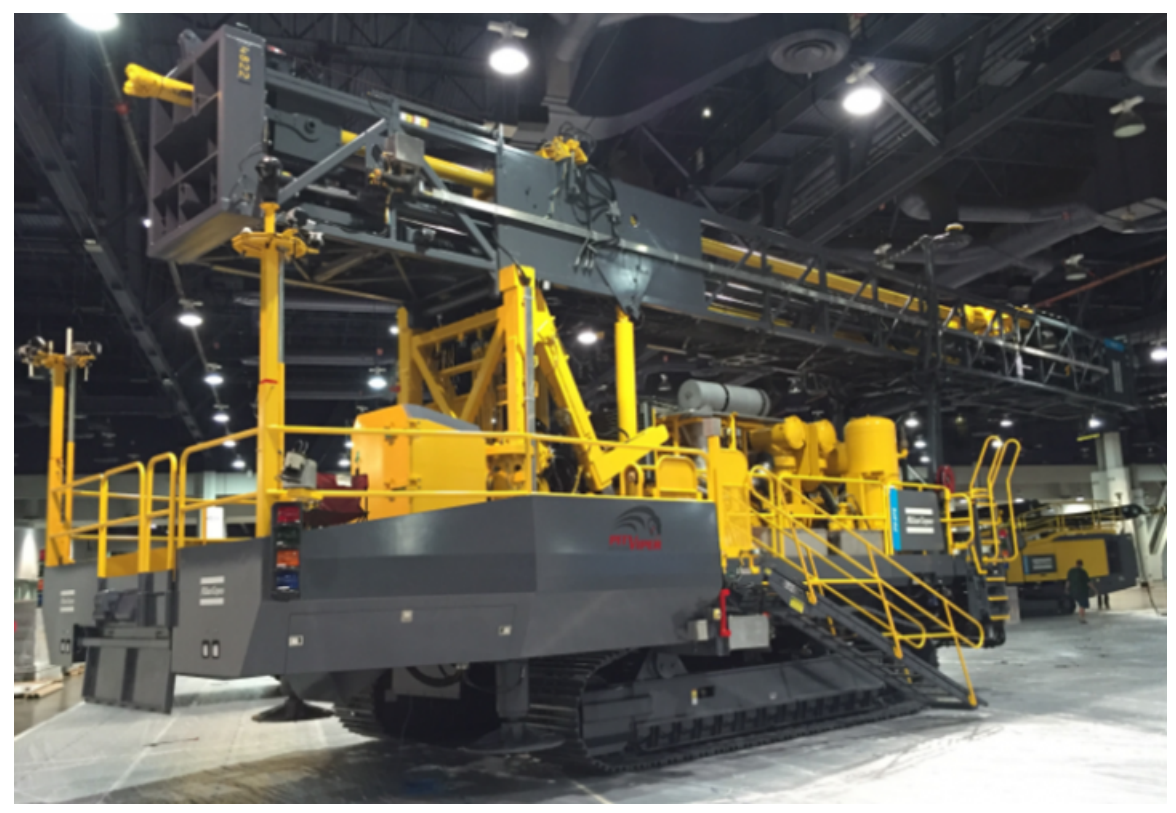

Fig. 2 Atlas Copco's fully autonomous and cabless surface blasthole drill, called the "Pit Viper 275", revealed at MINExpo International 2016, which can drill and reposition itself automatically according to a user-programmed drilling plan [courtesy of Atlas Copco Rock Drills AB, 2016].

in mining, have made underground mining an ideal domain for the application of modern techniques from the field of mobile robotics.

Perhaps the most high-profile example of robotics in underground mining is the automation of underground loaders-load-haul-dump (LHD) machines—and haul trucks. LHD machines are centre-articulated, diesel-driven, and hydraulicallyactuated vehicles that are used to transport materials from one location underground (usually a draw point) to another location (usually a dump point). The repetitive nature of this task makes it ideal for automation. Fig. 3 shows an Atlas Copco ST14 LHD machine autonomously tramming (i.e., driving) at the Kvarntorp underground mine near Örebro, Sweden. One unique challenge for underground robotics is the problem of accurate and real-time localization in environments where global infrastructure is unavailable (e.g., the absence of GNSS, available on surface). Although early autonomous tramming systems worked by outfitting the underground mine with infrastructure, such as signal-emitting cables, reflective strips, or light-emitting ropes, modern systems (such as the one shown in Fig. 3) are infrastructureless and rely only on the use of onboard sensors for mapping and underground navigation; see Marshall et al (2016, Section 59.3.2) and references therein.

Teleremote control or telerobotics (i.e., the operation of equipment from afar, but where a human remains part of the control loop) has found relatively widespread application in underground mining, for both LHD machines as well as for the operation of underground drilling machines (Hunter et al, 1996; Appelgren, 2003). 


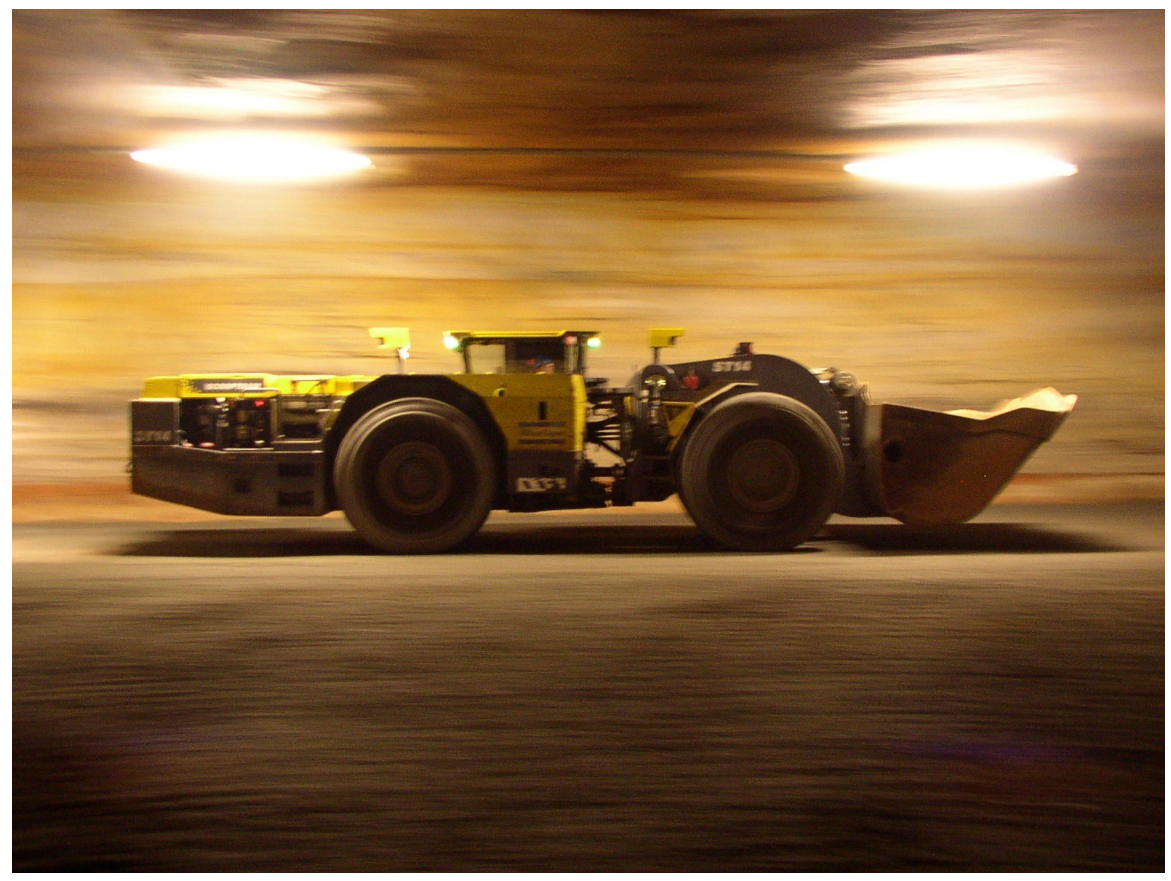

Fig. 3 An autonomous underground Atlas Copco ST14 load-haul-dump (LHD) machine at the Kvarntorp mine, Sweden [courtesy of Joshua Marshall, 2008].

Telerobotics has also been used for robotically-assisted explosives charging (i.e., loading drill holes with explosives) (Bonchis et al, 2014).

Robotic excavation-where a loader or other excavation machine is able to autonomously fill a bucket with a target medium-has posed a challenge for field roboticists dating back several decades. Currently still the job of humans, the problem of robotic excavation is particularly difficult to automate because of the dynamic and unpredictable bucket-rock interactions that can occur during the excavation process. In addition to varying material properties (e.g., density and hardness), solutions that work for homogeneous materials, such as soil and gravel, do not necessarily work for fragmented rock (common in mining), which can have a significant distribution of particle sizes (Marshall et al, 2008).

The robotic excavation problem can be broken down into two fundamental tasks: dig planning (i.e., where to dig) and dig execution and control (i.e., how to successfully and automatically dig). In surface mining and quarrying, dig planning is important (Magnusson and Almqvist, 2011). However, in underground mines where loading occurs at well-defined draw point locations, the focus is on dig execution and control. Although there has been much work on this subject, some examples of recent approaches include the use of admittance control (Dobson et al, 2016, 2017) and machine learning (Dadhich et al, 2016). 
Other applications of robotics in mining include the extensive use of simultaneous localization and mapping (SLAM) techniques to solve mapping and localization problems in underground environments where GNSS and other infrastructure-based localization systems are ineffective (e.g., see Magnusson et al, 2007; Zlot and Bosse, 2012; Lavigne and Marshall, 2012).

\section{Future Directions}

Despite a long history of incremental advances in the application of robotics to mining activities (Marshall et al, 2016), the mining industry has only recently begun to embrace robotics as a critical tool. Some large mining companies, including Rio Tinto, BHP Billiton, and Barrick Gold, to name a few, have recently incorporated robotics as an integral part of their business strategies. Some OEMs have also recognized the need for open and shared standards, such as International Rock Excavation Data Exchange Standard (IREDES) and even the Robot Operating System (ROS), thus allowing end users (i.e., mining companies) and technology developers to innovate and develop for their machines, as well as employ mixed fleets as a result of improved interoperability of hardware and software systems.

In future, we may see the increased use of smaller mobile robots for tasks such as surveying, mine rescue and recovery (Murphy et al, 2009), or perhaps even maintenance in harsh and remote environments. Undersea mining, using remotely operated underwater vehicles (ROVs), is currently a field of increasing technical and commercial interest (Bogue, 2015). Finally, the next great frontier for mining may be the exploration and exploitation of mineral resources beyond our own planet, on the Moon, Mars, asteroids, or other extraterrestrial bodies (e.g., see Bar-Cohen and Zacny, 2009; Moores et al, 2012; Cave, 2016).

\section{References}

Appelgren J (2003) Remote control and navigation systems. Mining \& Construction Magazine 2:16-19

Bar-Cohen Y, Zacny K (eds) (2009) Drilling in Extreme Environments: Penetration and Sampling on Earth and other Planets. WILEY-VCH Verlag GmbH \& Co. KGaA, Weinheim, Germany

Bogue R (2015) Underwater robots: A review of technologies and applications. Industrial Robot: An International Journal 42(3):186-191, DOI 10.1108/IR-012015-0010

Bonchis A, Duff E, Roberts J, Bosse M (2014) Robotic explosive charging in mining and construction applications. IEEE Transactions on Automation Science and Engineering 11(1):245-250, DOI 10.1109/TASE.2013.2241425 
Cave H (2016) Mining space rocks. Engineering \& Technology pp 46-49, DOI 10.1049/et.2016.0204

Chadwick J (1996) Autonomous mine truck. Mining Magazine 175(5):287-288

Dadhich S, Bodin U, Sandin F, Andersson U (2016) Machine learning approach to automatic bucket loading. In: 24th Mediterranean Conference on Control and Automation, pp 1260-1265, DOI 10.1109/MED.2016.7535925

Dobson AA, Marshall JA, Larsson J (2016) Admittance control for robotic loading: Underground field trials with an LHD. In: Barfoot TD, Wettergreen DS (eds) Field and Service Robotics: Results of the 10th International Conference, Springer International Publishing, pp 487-500, DOI 10.1007/978-3-319-27702-8

Dobson AA, Marshall JA, Larsson J (2017) Admittance control for robotic loading: Design and experiments with a 1-tonne loader and a 14-tonne load-haul-dump machine. Journal of Field Robotics 34(1):123-150, DOI 10.1002/rob.21654

Duff E, Caris C, Bonchis A, Taylor K, Gunn C, Adcock M (2010) The development of a telerobotic rock breaker. In: Howard A, Iagnemma K, Kelly A (eds) Field and Service Robotics, Springer Tracts in Advanced Robotics, vol 62, Springer Berlin Heidelberg, pp 411-420, DOI 10.1007/978-3-642-13408-1

Hunter D, Wells D, Chrystall K, Feighan P (1996) Achieving effective telerobotic control of industrial equipment. CIM Bulletin 89(1002):83-88

Lavigne NJ, Marshall JA (2012) A landmark-bounded method for large-scale underground mine mapping. Journal of Field Robotics 29(6):861-879, DOI $10.1002 /$ rob.21415

Lever P (2011) Automation and robotics. In: Darling P (ed) SME Mining Engineering Handbook, 3rd edn, Society for Mining, Metallurgy and Exploration (SME), chap 9.8

Magnusson M, Almqvist H (2011) Consistent pile-shape quantification for autonomous wheel loaders. In: Proceedings of the 2011 IEEE/RSJ International Conference on Intelligent Robots and Systems, pp 4078-4083, DOI 10.1109/IROS.2011.6095031

Magnusson M, Lilienthal A, Duckett T (2007) Scan registration for autonomous mining vehicles using 3D-NDT. Journal of Field Robotics 24(10):803-827, DOI 10.1002/rob.20204

Mansouri M, Andreasson H, Pecora F (2016) Hybrid reasoning for multirobot drill planning in open-pit mines. Acta Polytechnica 56(1):47-56, DOI 10.14311/APP.2016.56.0047

Marshall J, Murphy P, Daneshmend L (2008) Toward autonomous excavation of fragmented rock: Full-scale experiments. IEEE Transactions on Automation Science and Engineering 5(3):562-566, DOI 10.1109/TASE.2007.912709

Marshall JA (2010) Navigating the advances in underground navigation. CIM Magazine 5(4):20-21

Marshall JA, Bonchis A, Nebot E, Scheding S (2016) Robotics in mining. In: Siciliano B, Khatib O (eds) Springer Handbook of Robotics, 2nd edn, Springer International Publishing, chap 59, pp 1549-1576, DOI 10.1007/978-3-319-32552-1

Moores JE, Francis R, Mader M, Osinski G, Barfoot T, Barry N, Basic G, Battler M, Beauchamp M, Blain S, Bondy M, Capitan RD, Chanou A, Clayton J, 
Cloutis E, Daly M, Dickinson C, Dong H, Flemming R, Furgale P, Gammel J, Gharfoor N, Hussein M, Grieve R, Henrys H, Jaziobedski P, Lambert A, Leung K, Marion C, McCullough E, McManus C, Neish C, Ng H, Ozaruk A, Pickersgill A, Preston L, Redman D, Sapers H, Shankar B, Singleton A, Souders K, Stenning B, Stooke P, Sylvester P, Tornabene L (2012) A mission control architecture for robotic lunar sample return as field tested in an analogue deployment to the Sudbury impact structure. Advances in Space Research 50(12):1666 -1686, DOI 10.1016/j.asr.2012.05.008

Murphy RR, Kravitz J, Stover S, Shoureshi R (2009) Mobile robots in mine rescue and recovery. IEEE Robotics \& Automation Magazine 16(2):91-103, DOI 10.1109/MRA.2009.932521

Zlot R, Bosse M (2012) Efficient large-scale 3D mobile mapping and surface reconstruction of an underground mine. In: Proceedings of the 8th International Conference on Field and Service Robotics

\section{Cross-References}

Autonomous haulage

Autonomous tramming

Autonomous drilling

Robotic excavation

Underground mapping 